\title{
Changing spray-dried lactose-whey protein isolate particle structure with drying conditions
}

\author{
De Souza Lima, R. ${ }^{a^{*}}$; Guttierez, G. ${ }^{\text {a }}$ Arlabosse, P. ${ }^{\text {a }}$; Ré, M.-I. ${ }^{a}$ \\ aUniversité de Toulouse, IMT Mines Albi-Carmaux, CNRS UMR 5302, Centre \\ RAPSODEE, Campus Jarlard, 81013 Albi cedex 09, France
}

*E-mail of the corresponding author: rogerlima.w@gmail.com

\begin{abstract}
Spray drying has become not merely a drying process, but also an important tool for engineering solid structures, specially for multi-component feeds. In that way, it is important to know how the drying conditions and liquid formulations affect the particle final solid structure. In the present study, we investigated the changes on the solid structure of a spray-dried binary mixture of lactose and whey protein isolate under different process and formulation conditions. Particle morphology, diameter, porosity and occluded air were analyzed. Total solid content in the feed was the parameter of highest impact on the spray-dried particle's occluded air volume.
\end{abstract}

Keywords: spray drying; solid structure; porosity; hollow particless. 


\section{Introduction}

The first significant industrial use of spray drying concerned the dairy industry in the 1920s. This operation first attracted attention for its capacity of quickly producing particulate material with controllable size distribution, bulk density, moisture content and the possibility of drying heat-sensitive substances [1]. For many years, spray drying had been mainly seen as solely a drying operation to produce large amounts of powder, remove most of the feed's solvent and enhance product storage and stability.

However, this perception changed over the years driven by the increasing demand for particles with engineered end-use properties, that is to say particles with improved properties like dissolution rate, controlled release, flowability, wettability, compactibility and coating $[2,3]$. Therefore, spray drying has become nowadays a tool for designing solid structures, specially from multi-component feeds.

The aforementioned particle properties are affected by the drying parameters, such as air temperature, air humidity and initial droplet size, as well as the feed liquid state (solution, emulsion, suspension), nature of the substances to be dried and their concentration [4]. To accurately design solid particles, it is important to understand how the particle solid structure is influenced by the drying conditions and feed composition.

The aim of the present work was to investigate the effect of some drying and formulation parameters on the solid structure of particles produced by spray drying. An aqueous solution of lactose and whey protein isolate (model solution in the food industry) was dried under different air inlet temperatures, nozzle diameters and initial solid loads. The variation of particle morphology, diameter, porosity and occluded air were analyzed.

\section{Materials and Methods}

\subsection{Materials}

$\alpha$-lactose monohydrate and whey protein isolate (WPI) were kindly provided by PierreFabre Laboratory (France) and Lactalis (France), respectively, and used as received.

\subsection{Methods}

\subsubsection{Solution preparation}

The sample solutions were prepared by mixing lactose and WPI powders in distilled water at a constant protein-to-sugar mass ratio of 50:50. The total dissolved solid content in the liquid feed varied from 10,20 to $26 \% \mathrm{w} / \mathrm{w}$. In order to completely dissolve the solutes and to avoid protein denaturation, the samples were heated at $30{ }^{\circ} \mathrm{C}$ and gently agitated with a magnetic stirrer for 8 hours. 


\subsubsection{Spray drying}

A laboratory-scale spray dryer (B-290 Advanced, Büchi, Switzerland) was used to spray dry the sample solutions. The air inlet temperature was fixed at $103{ }^{\circ} \mathrm{C}$ or $120{ }^{\circ} \mathrm{C}$. Two different nozzle diameters were used, $0.5 \mathrm{~mm}$ and $2.0 \mathrm{~mm}$. The experiments were carried out with an aspiration rate of $95 \%$ with a corresponding air flow rate of $33.25 \mathrm{~m}^{3} / \mathrm{h}$ and a feed rate of $4.27 \mathrm{~mL} / \mathrm{min}$. The powder collected after drying was stored at room temperature in a flask. Table 1 represents the experimental conditions employed in the present work.

Table 1. Sample solutions parameters and drying conditions

\begin{tabular}{cccccc}
\hline Sample & $\begin{array}{c}\text { Lactose } \\
\text { percentage } \\
(\% \mathbf{~ w / w )}\end{array}$ & $\begin{array}{c}\text { WPI } \\
\text { percentage } \\
(\% \mathbf{w} / \mathbf{w})\end{array}$ & $\begin{array}{c}\text { Total solid } \\
\text { content } \\
(\mathbf{\%} \mathbf{w} / \mathbf{w})\end{array}$ & $\begin{array}{c}\text { Nozzle } \\
\text { diameter } \\
(\mathbf{m m})\end{array}$ & $\begin{array}{c}\text { Air inlet } \\
\text { temperature } \\
\left({ }^{\circ} \mathbf{C}\right)\end{array}$ \\
\hline S1 & 5.0 & 5.0 & 10.0 & 2.0 & 103.0 \\
S2 & 9.9 & 9.9 & 19.8 & 2.0 & 103.0 \\
S3 & 13.0 & 13.0 & 26.0 & 2.0 & 103.0 \\
S4 & 10.0 & 10.0 & 20.0 & 0.5 & 120.0 \\
\hline
\end{tabular}

\subsubsection{Spray-dried particles characterization}

The particle diameter was evaluated by laser diffraction (Malvern Mastersize 3000, Malvern Instruments) after dispersing the powder in 2-propanol. The particle size distribution was calculated with the Mie theory using the refractive index values of $\mathrm{n}=$ 1.378 for 2-propanol and $n=1.57$ for the spray-dried particles.

To assess the particle morphology, the spray-dried samples were examined with scanning electron microscopy (SEM) (ESEM FEG Philips). The acceleration voltage was $8 \mathrm{kV}$. The particles were placed on an adhesive carbon tape and sputter-coated with platinum.

Liquid pycnometry was employed in order to evaluate the apparent density of the spraydried powder. The apparent density was calculated by knowing exactly the mass of powder and 2-isopropanol inserted into the pycnometer. The measurements were done in triplicate.

Helium pycnometry (Accupyc 1340, Micromeritics) was used to determine the particle true density. Two grams of powder were dried under vacuum in an oven at $70{ }^{\circ} \mathrm{C}$, to evaporate any remaining moisture, and added to the pycnometer's measuring cell. The true density was obtained after 25 cycles of filling-draining helium in the measurement cell. 


\section{Results and discussion}

Lactose is a compound frequently present in spray drying of dairy produts, since it is the main carbohydrate in bovine milk. This sugar is also employed as protective agent when stress-sensitive substances are spray dried, like whey protein [5].

The different drying conditions presented in Table 1 did not cause any change in the particle morphology. The spray dried powders presented a hollow core with a wrinkled surface, as can be seen from the SEM micrographs in Figure 1. A wrinkled morphology was also observed in previous studies with protein-to-sugar mass ratios of 70:30 [6] and 80:20 [5]. Spray-dried skim milk [7] also presented the same surface roughness.

The laser diffraction results in Table 2 are given in volume fractions. The particle size distribution is represented by three percentages of particles having at most the indicated diameters. The Span number displays the distribution width. From these measurements, it is possible to observe as expected an increase in the mean spray-dried particle size with more concentrated feed formulations.. The solid crust appears sooner on more concentrated liquid droplets in comparison to more diluted ones, due to the proximity to saturation. Therefore, the resulting external diameter remains bigger.

Table 2. Laser diffraction measurements for the mixture $50 \%$ lactose - $50 \%$ whey protein isolate ( $w / w$, on dry basis) on the different samples

\begin{tabular}{|c|c|c|c|c|c|c|}
\hline Sample & $\begin{array}{c}\text { Total solid } \\
\text { content } \\
(\% \mathrm{w} / \mathrm{w})\end{array}$ & $\begin{array}{c}\text { Volume mean } \\
\text { diameter } \\
\text { d-4,3 }(\mu \mathrm{m})\end{array}$ & $\begin{array}{l}d-10 \\
(\mu \mathrm{m})\end{array}$ & $\begin{array}{l}d-50 \\
(\mu \mathrm{m})\end{array}$ & $\begin{array}{l}\text { d-90 } \\
(\mu \mathrm{m})\end{array}$ & Span \\
\hline $\mathrm{S} 1$ & 10.0 & $9.1 \pm 0.0$ & $2.6 \pm 0.0$ & $8.9 \pm 0.0$ & $15.4 \pm 0.1$ & $1.4 \pm 0.0$ \\
\hline S2 & 19.8 & $10.5 \pm 0.1$ & $2.8 \pm 0.0$ & $10.3 \pm 0.0$ & $17.9 \pm 0.1$ & $1.5 \pm 0.0$ \\
\hline S3 & 26.0 & $12.3 \pm 0.1$ & $2.6 \pm 0.0$ & $12.1 \pm 0.1$ & $21.8 \pm 0.1$ & $1.6 \pm 0.0$ \\
\hline S4 & 20.0 & $5.4 \pm 0.0$ & $1.6 \pm 0.0$ & $5.2 \pm 0.0$ & $9.5 \pm 0.0$ & $1.5 \pm 0.1$ \\
\hline
\end{tabular}

The measure of apparent density from the liquid pycnometry includes open and closed pores in the particles. The helium pycnometry gives the particle true density from the adsorption of helium to the solid's surface through the open pores. Due to the low-porous nature of the present spray-dried samples, the presence of closed pores can be neglected for the sake of density and porosity calculations. These density values are presented in Table 3 . It is important to note that the particles (micrographs in Figure 1) show a densely packed crust region, so one can suggest that the porosity estimations take into account mainly the air fraction presented in the particle hollow core. 
(a)

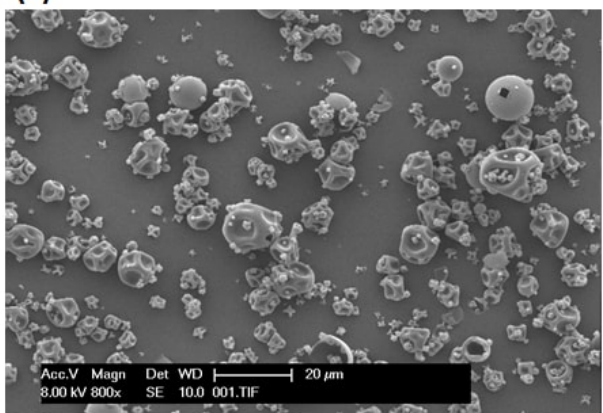

(c)

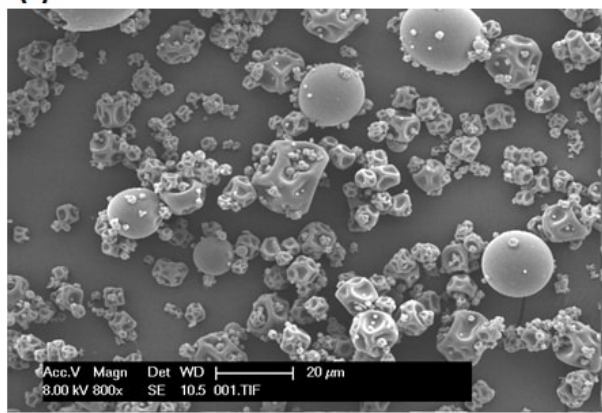

(e)

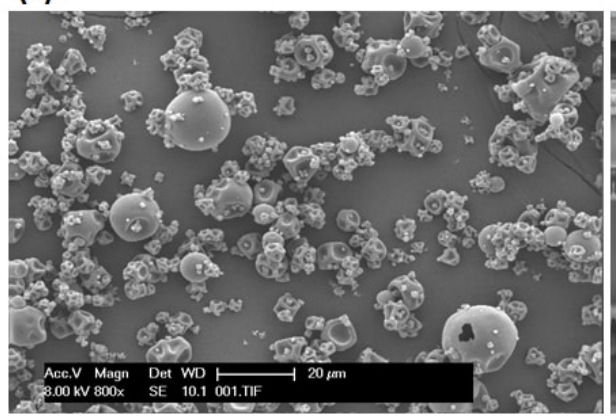

(b)

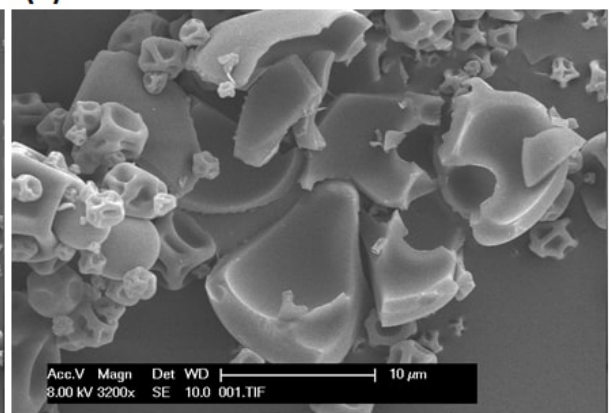

(d)

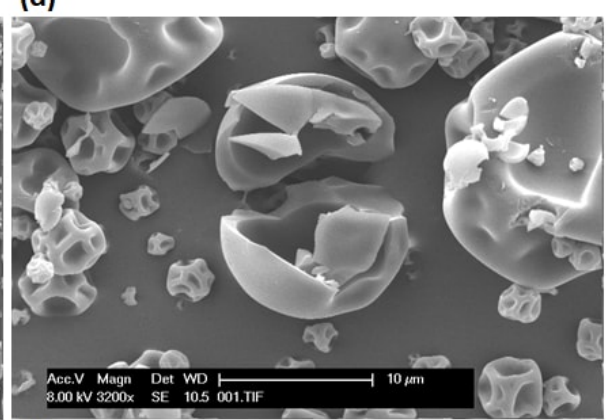

(f)

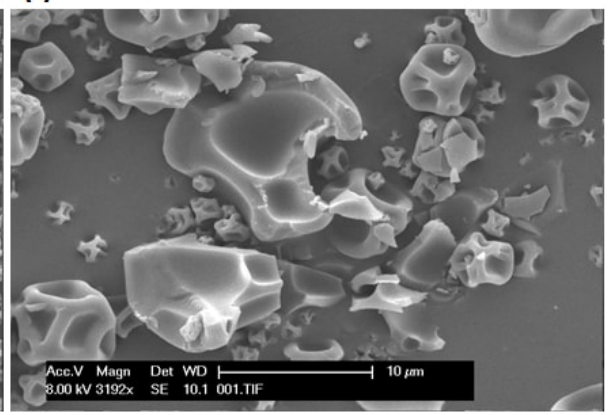

Figure 1. SEM micrographs of spray-dried lactose-whey protein isolate particles illustrating the same trend of wrinkled surface produced from droplets of different total solid content. $10 \% w / w(a-b), 20 \% w / w(c-d), 30 \% w / w(e-f)$

For the purpose of visualization, the density results were written in terms of particle porosity, and thus occluded air, so that a modification of the particle crust can be examined. To calculate the porosity, the mass of air contained in the particle's pores was neglected. In that way, the apparent and true densities were used to evaluate the porosity, as indicated in Equation 1. 
Table 3. Evolution of occluded air measured from the spray-dried particle's porosity and apparent density

\begin{tabular}{|c|c|c|c|c|c|}
\hline Sample & $\begin{array}{c}\text { Total solid } \\
\text { content } \\
(\% \mathrm{w} / \mathrm{w})\end{array}$ & $\begin{array}{c}\text { Apparent } \\
\text { density } \\
\left(\mathrm{g} / \mathrm{cm}^{3}\right)\end{array}$ & $\begin{array}{c}\text { True } \\
\text { density } \\
\left(\mathrm{g} / \mathrm{cm}^{3}\right)\end{array}$ & Porosity & $\begin{array}{l}\text { Occluded air } \\
\qquad\left(\mathrm{cm}^{3} / \mathrm{g}\right)\end{array}$ \\
\hline S1 & 10.0 & $0.81 \pm 0.0$ & $1.37 \pm 0.0$ & 0.41 & 0.50 \\
\hline S2 & 19.8 & $0.88 \pm 0.0$ & $1.30 \pm 0.0$ & 0.32 & 0.36 \\
\hline S3 & 26.0 & $0.92 \pm 0.0$ & $1.25 \pm 0.0$ & 0.26 & 0.28 \\
\hline S4 & 20.0 & $0.86 \pm 0.0$ & $1.37 \pm 0.0$ & 0.37 & 0.43 \\
\hline
\end{tabular}

$$
\varphi=\frac{\rho_{\text {true }}-\rho_{\text {apparent }}}{\rho_{\text {true }}}
$$

Where $\varphi$ is the particle porosity. The volume of occluded air in the particle per gram of powder can be calculated from the porosity as follows,

$$
V_{\text {occluded air } / \text { g powder }}=\varphi \frac{1}{\rho_{\text {apparent }}}
$$

It is interesting to note from Table 3 that an increase of approximately $40 \%$ on the particle occluded air was accomplished by reducing the total solid content from $26 \% \mathrm{w} / \mathrm{w}$ to $10 \%$ $\mathrm{w} / \mathrm{w}$, for the same air inlet temperature and nozzle diameter. However, an increase of only $10 \%$ on the particle occluded air was obtained by modifying the air inlet temperature and the nozzle size from $\left[103{ }^{\circ} \mathrm{C}, 2 \mathrm{~mm}\right]$ to $\left[120^{\circ} \mathrm{C}, 0.5 \mathrm{~mm}\right]$, for the same total solid fraction.

The displayed occluded air results along with the mean particle diameters (d-4.3) from Table 2 give an indirect qualitative information about the particle crust width. When comparing the samples S1 and S3, the mean particle diameter is relatively close, but the particle occluded air difference is more important, as mentioned in the previous paragraph. Consequently, one can suggest that the lower solid content on the particles from sample S1 generated a thinner crust compared to that of the particles from S3.

The amount of occluded air in the particle is an important issue in cases when there are oxidation-sensitive compounds present in the particle solid structure. In that way, to avoid a particle inner oxidation, a reduction of the occluded air should be considered [8]. 


\section{Conclusions}

In the present study, particles containing an equal mixture of lactose and whey protein isolate were obtained through spray drying. In order to observe changes in the particle solid structures, the sample solutions were spray dried under different total solid contents, air inlet temperatures and nozzle diameters. The resulting particles were analyzed through scanning electron microscopy, laser diffraction, liquid pycnometry and helium pycnometry. In that way, the particle morphology, diameter, porosity and occluded air could be assessed.

It was observed that a hollow and wrinkled particle morphology was obtained from all the spray dried samples. A slight increase in the mean particle diameter was observed with higher solid contents. A change in the total solid content had a higher impact on the particle's occluded air than the coupled air inlet temperature and nozzle diameter. It is important to note that the porosity and occluded air estimations were related to the quantity of air present in the particle hollow core, due to the low-porous nature of the particle's crust obtained. A higher occluded air amount can lead to oxidation issues if there are sensitive substances in the particle solid structure. A possible solution would then be the use of higher solid contents in the liquid feed, to generate particles with a lower occluded air volume.

\section{References}

[1] Masters, K. Spray Drying Handbook. 5th edition. Longman Scientific \& Technical, 1991, p. 725.

[2] Ré, M.-I. Formulating Drug Delivery Systems by Spray Drying. Drying Technology 2006, 24.4; 433-446.

[3] Munoz-Ibanez, M. et al. The microstructure and component distribution in spray-dried emulsion particles. Food Structure 2016, 8; 16-24.

[4] Nandiyanto, A. B. D.; Okuyama, K. Progress in developing spray-drying methods for the production of controlled morphology particles: from the nanometer to submeter size ranges. Advanced Powder Technology 2011, 22.1 ; 287-296.

[5] Haque, M. A.; Adhikari, B.; Putranto, A. Predictions of drying kinetics of aqueous droplets containing WPI-lactose and WPI -trehalose by application of composite reaction engineering approach (REA). Journal of Food Engineering 2016, 189; 29-36.

[6] Haque, M. A.; Chen, J.; Aldred, P.; Adkikari, B. Drying and denaturation characteristics of whey protein isolate in the presence of lactose and trehalose. Food Chemistry 2015, 177; 8-16.

[7] Kim, E. H. -J.; Chen, X. D.; Pearce, D. On the mechanisms of surface formation and the surface compositions of industrial milk powders. Drying Technology 2003, 21; $265-278$.

[8] Keogh, M. K.; O’Kennedy, B.T.; Kelly, J.; Auty, M. A.; Kelly, P. M.; Fureby, A.; 
Haahr, A. -M.Stability to oxidation of spray-dried fish oil powder microencapsulated using milk ingredients.Food Chemistry and Toxicology 2001, 66; 217-224. 